\title{
Design of magnetic bearings for turbo refrigerant compressors
}

\author{
Cheol Hoon Park ${ }^{a}$, Sang Kyu Choi and Sang Yong Ham \\ Advanced Manufacturing Systems Research Division, Korea Institute of Machinery and Materials, Korea
}

Received 18 December 2013, Accepted 29 April 2014

\begin{abstract}
Magnetic bearings are oil-free bearings that are widely employed in turbo machineries such as turbo refrigerant compressors in order to eliminate lubrication systems, avoid contamination, and increase efficiency. We have developed a 145 refrigerant ton (RT)-class turbo refrigerant compressor using homopolar-type radial hybrid magnetic bearings (HMBs) and thrust magnetic bearings. The thrust magnetic bearing comprises a thrust HMB and a permanent magnet that generate downward forces to overcome high upward thrust forces of $2000 \mathrm{~N}$ at $21000 \mathrm{rpm}$. A test rig and controller for the compressor with magnetic bearings were fabricated, and rotordynamics such as the unbalance response and axial displacement were investigated. Rotordynamics analyses using the finite element method predicted that the 1st bending mode is located at a high frequency with sufficient margin from the operating speeds. Further, the zero-to-peak displacement caused by the unbalanced response was sufficiently small. The rotor was stably supported with few vibrations across the entire range of the operational speeds. Our results demonstrate that the advantages of oil-free bearings can be easily exploited in turbo machineries such as turbo refrigerant compressors by adopting HMBs.
\end{abstract}

Key words: Hybrid magnetic bearing / turbo refrigerant compressor / oil-free bearing / rotordynamics / unbalance response

\section{Introduction}

Turbo refrigerant compressors are key components of many heating, ventilation, and air conditioning (HVAC) systems such as air conditioners used in buildings or vehicles, temperature-humidity controllers, environmental test equipment, and food storage systems. Turbo refrigerant compressors employ oil-free bearings such as air foil bearings or magnetic bearings since they can be operated continuously in the absence of lubrication systems; moreover, the refrigerant is not contaminated by any lubricant oil $[1,2]$. However, in the case of air foil bearings, friction exists between the bearing and rotor at startup and shutdown, and solid lubrication is required [3]. Furthermore, the load capacity of air foil bearings is quite low, and they decrease the stability because they provide low damping [4]. On the other hand, magnetic bearings have several advantages. The absence of friction reduces wear at all operation speeds including startup and shutdown, thereby reducing the maintenance costs. Further, the energy efficiency is higher because the friction loss is less than $1 / 500$ th that of typical oil bearings.

Magnetic bearings are classified into three types depending on how the magnetic flux is generated: active

${ }^{a}$ Corresponding author: parkch@kimm.re.kr magnetic bearings (AMBs) that use only electromagnets, permanent magnetic bearings (PMBs) that use only permanent magnets, and hybrid magnetic bearings (HMBs) that use a combination of permanent magnets and electromagnets [5]. PMBs do not require energy, but they are unsuitable for vibration control owing to their low stiffness and damping; without sufficient damping, the stability of a rotor against synchronous and harmonic vibrations due to unbalance cannot be guaranteed [6,7]. AMBs exhibit fast dynamic responses, but they require a continuous bias current to generate bias flux, which reduces their efficiency. HMBs combine the advantages of both PMBs and AMBs. They do not require a bias current because the permanent magnet located adjacent to the electromagnetic core generates a bias flux; furthermore, since they can generate a greater magnetic force than AMBs with the same amount of current, their efficiency is higher. Several manufacturers have recently begun producing commercial compressors with magnetic bearings. Hirai et al. (2010) have developed an oil-free cryogenic turbo-expander with AMBs [8], and Fang et al. (2012) have developed passive thrust magnetic bearings for applications to high-speed compressors [7].

In this study, we present a design procedure for magnetic bearings that can support a 145 refrigerant ton (RT)-class turbo refrigerant compressor. HMBs are 


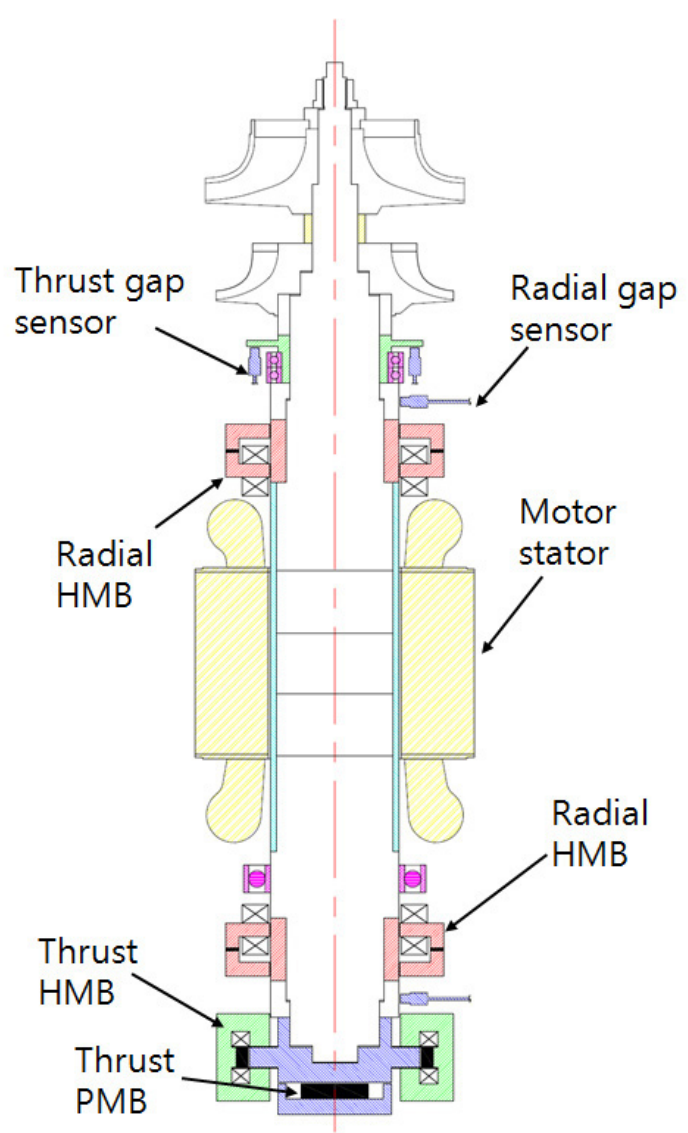

Fig. 1. Configuration of turbo refrigerant compressor using hybrid magnetic bearings; HMB: hybrid magnetic bearing; PMB: permanent magnetic bearing.

employed in this study in order to minimize the size of the magnetic bearings and maximize efficiency. We used both homopolar-type radial HMBs and thrust HMBs comprising both permanent and electromagnets. Our magnetic bearings are designed to support a $2000 \mathrm{~N}$ thrust force generated by a compressor at an operating speed of $21000 \mathrm{rpm}$. We have also designed a controller for the magnetic bearings. Further, we simulated rotordynamics such as the critical speed and unbalance response by using a finite-element method. A test rig and controller were also fabricated, and the unbalance responses and axial displacements were investigated.

\section{Configuration of turbo refrigerant compressor}

Figure 1 shows a simple configuration of the rotor and magnetic bearings of an oil-free turbo refrigerant compressor consisting of a shaft, impellors, magnetic bearings, and a high-speed synchronous motor. The magnetic bearings comprise radial magnetic bearings and thrust magnetic bearings. HMBs are employed in the turbo refrigerant compressor to minimize the size of the magnetic bearings and maximize the efficiency. The thrust

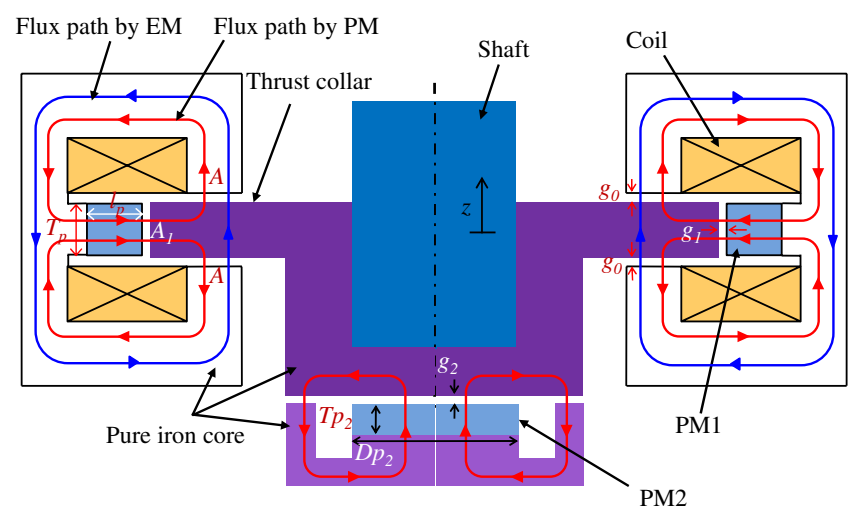

Fig. 2. Configuration of thrust $\mathrm{HMB} / \mathrm{PMB}$ and flux paths with permanent magnets.

magnetic bearing used to overcome the high thrust forces consists of a thrust HMB and PMB.

The rotor is setup vertically so that the radial magnetic bearings do not have to support the rotor weight, thereby minimizing the required force. Moreover, this setup reduces the force required by the thrust magnetic bearings because the gravitational force generated by the rotor acts in a direction opposite to the upward thrust force generated by the compressor.

\section{Design of magnetic bearings}

\subsection{Design of thrust magnetic bearings}

To design the thrust magnetic bearings, first, the thrust force that needs to be supported must be identified. Because the turbo refrigerant compressor is of the vertical-rotor type, the sum of the thrust forces generated by the compressor and rotor weight can be considered as the total thrust force that needs to be supported. The rotor mass was predicted to be $\sim 22 \mathrm{~kg}$ and the thrust force generated by the compressor at the operating speed of $21000 \mathrm{rpm}$ was predicted to be maximum of $2000 \mathrm{~N}$. Therefore, the thrust force ranges from $-200 \mathrm{~N}$ at standstill to $1800 \mathrm{~N}$ at the operating speed of $21000 \mathrm{rpm}$.

Figure 2 shows the configuration of the thrust magnetic bearing. A double-acting-type thrust HMB is used to generate dynamic forces to compensate for the pulsations caused by the thrust force generated by compressor; it dynamically controls the magnetic force by changing the current. A thrust PMB is located at the end of the rotor to generate a bias force in a direction opposite to the thrust force generated by the compressor.

A ring-shaped permanent magnet (PM1), which is radially magnetized and generates bias fluxes for the HMB, is positioned in the HMB stator made of pure iron. Two serially connected ring-shaped coils are located in the upper and lower sides of the HMB stator. A PMB with coin-shaped permanent magnet (PM2) is located inside the pure iron stator with an air gap, $g_{2}$, between itself and the end of the rotor [9]. The pure iron structure of the thrust collar and the U-shaped core attached at the 
Table 1. Design requirements for thrust hybrid magnetic bearing $(\mathrm{HMB})$ and permanent magnetic bearing (PMB).

\begin{tabular}{lc}
\hline Parameter & Value \\
\hline Thrust force to be supported & $-200-1800$ \\
Force requirement for HMB and PMB [N] & $-1800-200$ \\
Bias force by PMB [N] & -1000 \\
Dynamic force by HMB [N] & $-2000-2000$ \\
Net magnetic force by HMB and PMB [N] & $-3000-1000$ \\
\hline
\end{tabular}

Table 2. Specifications for designed thrust HMB and PMB.

\begin{tabular}{|c|c|c|}
\hline \multicolumn{2}{|c|}{ Parameter } & Value \\
\hline \multicolumn{2}{|c|}{ Air gap between pole face and thrust collar, $g_{0}[\mathrm{~mm}]$} & 0.6 \\
\hline \multicolumn{2}{|c|}{ Current range $[\mathrm{A}]$} & $-7-7$ \\
\hline \multicolumn{2}{|l|}{ Area of pole face $\left[\mathrm{m}^{2}\right]$} & $4.04 \mathrm{e}-3$ \\
\hline \multicolumn{2}{|l|}{ Number of turns } & 40 \\
\hline \multirow{4}{*}{$\begin{array}{l}\text { Permanent magnet } \\
\text { for bias flux }\end{array}$} & Air gap, $g_{3}[\mathrm{~mm}]$ & 1 \\
\hline & Inner diameter $[\mathrm{mm}]$ & 114 \\
\hline & Out diameter $[\mathrm{mm}]$ & 130 \\
\hline & Thickness, $T_{\mathrm{p}}[\mathrm{mm}]$ & 13 \\
\hline \multirow{3}{*}{$\begin{array}{l}\text { Permanent magnet } \\
\text { for bias force }\end{array}$} & Air gap, $g_{2}[\mathrm{~mm}]$ & 0.8 \\
\hline & Diameter, $D p_{2}[\mathrm{~mm}]$ & 40 \\
\hline & Thickness, $T p_{2}[\mathrm{~mm}]$ & 10 \\
\hline \multicolumn{2}{|c|}{ Residual flux density of permanent magnet, $B r[\mathrm{~T}]$} & 1.2 \\
\hline \multicolumn{2}{|c|}{ Current gain, Kti $\left[\mathrm{N}^{-\mathrm{A}^{-1}}\right]$} & $2.99 \mathrm{e} 2$ \\
\hline \multicolumn{2}{|c|}{ Position gain, Ktx $\left[\mathrm{N} \cdot \mathrm{m}^{-1}\right]$} & $-1.33 \mathrm{e} 5$ \\
\hline
\end{tabular}

end of the rotor serves as the flux path from the HMB and $\mathrm{PMB}$ to the rotor. The net force acting on the thrust collar from the thrust HMB is given by (1), and it is explained in detail in reference [10].

$$
\begin{aligned}
F_{\text {thrust }}= & \frac{\mu_{0} A}{2}\left(\left(\frac{l_{\mathrm{p}} H_{\mathrm{c}}}{\left(g_{0}-z\right)+2 g_{1}+\frac{2 l_{\mathrm{p}}}{\mu_{\mathrm{p}}}}+\frac{N i}{g_{0}}\right)\right. \\
& \left.-\left(\frac{l_{\mathrm{p}} H_{\mathrm{c}}}{\left(g_{0}+z\right)+2 g_{1}+\frac{2 l_{\mathrm{p}}}{\mu_{\mathrm{p}}}}-\frac{N i}{g_{0}}\right)\right)
\end{aligned}
$$

Here, $l_{\mathrm{p}}$ is the radial length of the PM; $H_{\mathrm{c}}$, the coercivity of the PM; $\mu_{0}$, the magnetic permeability of free space, $\mu_{\mathrm{p}}$, the relative magnetic permeability of the PM; $g_{1}$, the air gap length between the outer side of the thrust collar and inner side of the PM; $A$, the area of the upper or lower pole face; $N$, the number of coil turns per pole; $I$, the current to the EM; $g_{0}$, a nominal gap; and $z$, the vertical displacement of the shaft. The thrust HMB and PMB were designed based on the requirements listed in Table 1 by referring to previous studies [9-14], and their specifications are listed in Table 2 . The dynamic force required by the thrust HMB is determined to have sufficient range for the net magnetic force generated by the HMB and PMB to have a safety factor exceeding 1.5.

To check the design validity, a magnetic flux density analysis was performed for 3 cases using electromagnetic
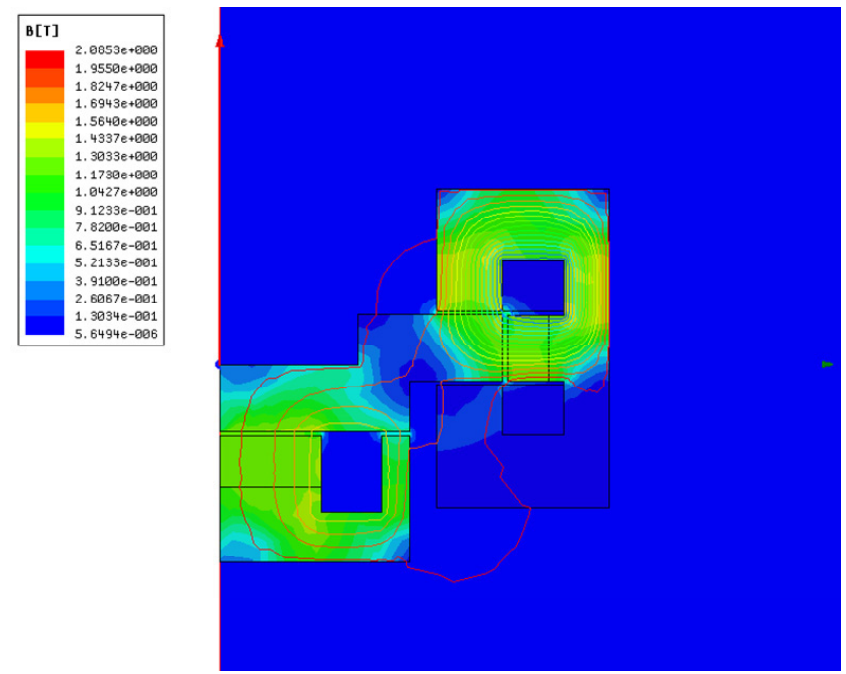

Fig. 3. Magnetic flux density analysis of thrust HMB and PMB with 7 A current.

Table 3. Analysis results for magnetic forces of thrust HMB depending on conditions.

\begin{tabular}{lc}
\hline \multicolumn{1}{c}{ Condition } & Magnetic force $[\mathrm{N}]$ \\
\hline Force by PMB only & -983 \\
Force by HMB only with 7 A current & 2003 \\
Force by PMB and HMB with 7 A current & 1273 \\
\hline
\end{tabular}

analysis software, MAXWELL, as shown in Figure 3. The analysis results, listed in Table 3, show that this design successfully generated almost the same forces as given in the design requirements.

\subsection{Design of radial hybrid magnetic bearings}

As in the design procedure of thrust magnetic bearings, we first need to identify the radial force to be supported. The gravity force generated by the rotor does not have to be considered to estimate the force required by the radial HMB because the turbo refrigerant compressor is of the vertical-rotor type. Two types of radial forces have to be considered in this system. The first is the attractive force that acts on the cylindrical surface of the thrust collar from PM1 when the centers of the thrust collar and PM1 are not identical. If the gap between the cylindrical surface of the thrust collar and PM1 is not constant, an attractive force will exist in the smaller gap area. To calculate this force, $3 \mathrm{D}$ electromagnetic analysis was performed under $0.3-\mathrm{mm}$ eccentric condition, which is a severe condition, and the result was found to be $\sim 110 \mathrm{~N}$. The other force is the unbalanced force generated by the high-speed rotor. This force is calculated under the ISO 1940 G2.5 specifications that are applied to turbo compressors; the unbalanced force for a $22-\mathrm{kg}$ rotor operating at $21000 \mathrm{rpm}$ was found to be $\sim 123 \mathrm{~N}$.

The radial magnetic bearing is of HMB type, as shown in Figure 4. A square-shaped permanent magnet (PM3) is inserted between the pure iron cores. The coils of the 


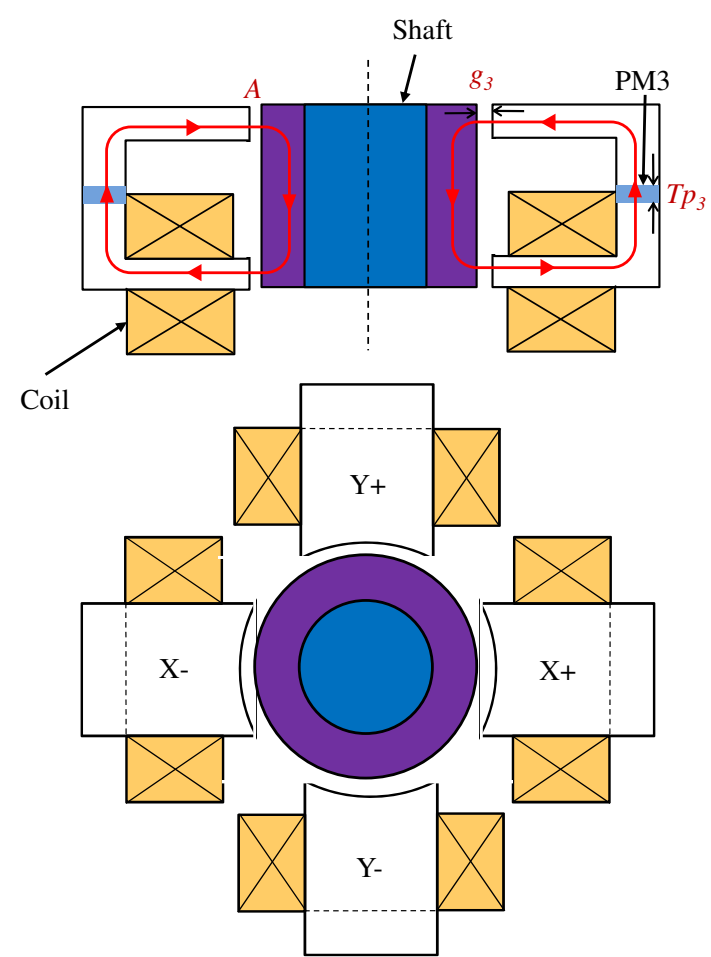

Fig. 4. Configuration of radial HMB and flux path by PM3.

Table 4. Design requirements for radial HMB.

\begin{tabular}{lc}
\hline \multicolumn{1}{c}{ Item } & Value \\
\hline Magnetic force against attractive force between & 110 \\
thrust collar and PM1 [N] & 123 \\
Magnetic force against unbalance force [N] & 233 \\
Net magnetic force by radial HMB [N] & \\
\hline
\end{tabular}

electromagnet pairs $-(\mathrm{X}+, \mathrm{X}-)$ and $(\mathrm{Y}+, \mathrm{Y}-)-$ are serially connected, and the magnetic flux density is controlled by both the direction and amount of current. The net $x$-directional force acting on the shaft by the radial HMB is given by (2).

$$
\begin{aligned}
F_{\text {radial }}= & \mu_{0} A\left(\left(\frac{T p_{3} H_{\mathrm{c}}+N i}{2\left(g_{3}-x\right)+T p_{3}}\right)^{2}\right. \\
& \left.-\left(\frac{T p_{3} H_{\mathrm{c}}-N i}{2\left(g_{3}+x\right)+T p_{3}}\right)^{2}\right)
\end{aligned}
$$

Here, $g_{3}$ is a nominal gap; $x$, the $x$-directional displacement of the shaft; and $T p_{3}$, the thickness of PM3. The requirements are listed in Table 4 , and on their basis, the specifications of the designed radial HMB are listed in Table 5. The dynamic force requirements of the radial HMB have sufficient range for the net magnetic force generated by the HMB to have a safety factor of 2 . The magnetic flux density analysis shown in Figure 5 predicts that this design will generate $232 \mathrm{~N}$ at $10 \mathrm{~A}$ current, which is almost the same force as the design requirements.
Table 5. Specifications for designed radial HMB.

\begin{tabular}{lc}
\hline \multicolumn{1}{c}{ Item } & Value \\
\hline Air gap between pole face and rotor, $g_{3}[\mathrm{~mm}]$ & 0.4 \\
Current range $[\mathrm{A}]$ & $-10-10$ \\
Area of pole face $\left[\mathrm{m}^{2}\right]$ & $3.60 \mathrm{e}-4$ \\
Number of turns & 90 \\
Thickness of permanent magnet, $T p_{3}[\mathrm{~mm}]$ & 13 \\
Residual flux density of permanent magnet, $B r[\mathrm{~T}]$ & 0.95 \\
Current gain, $K r i\left[\mathrm{~N} . \mathrm{A}^{-1}\right]$ & 26.9 \\
Position gain, $K r x\left[\mathrm{~N} \cdot \mathrm{m}^{-1}\right]$ & $-2.76 \mathrm{e} 5$ \\
\hline
\end{tabular}

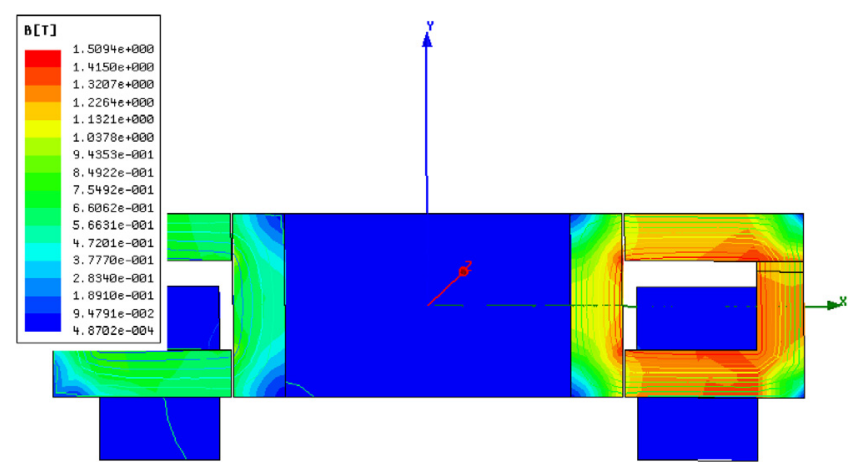

Fig. 5. Magnetic flux density analysis of radial HMB with 10 A current.

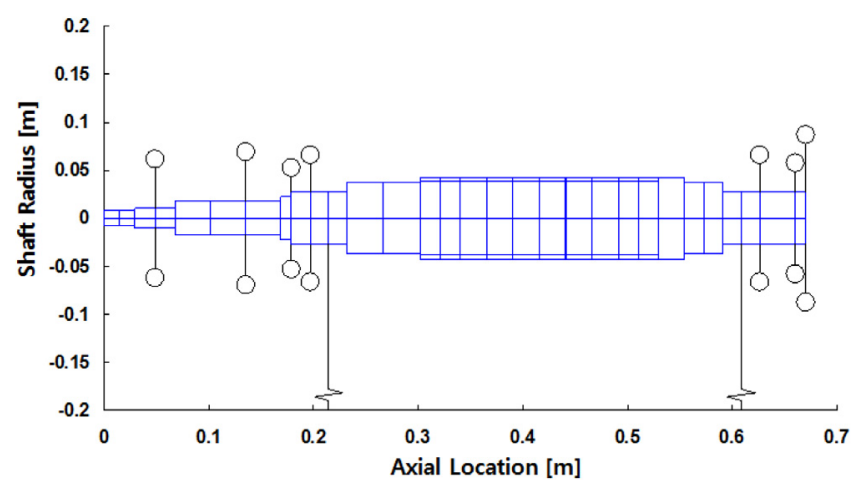

Fig. 6. Finite element method model of rotordynamics analyses.

\section{Rotordynamics analysis}

The flexible rotor shown in Figure 1 is divided into 34 elements, as shown in Figure 6, to analyze its rotordynamics using the finite element method. All the other components on the rotor except for the shaft are considered as added masses. The analytical model for the rotor supported by the radial HMB can be obtained by combining this finite element model and the linearized model of the radial HMB [15]. Based on our analytical model, a control block diagram with a proportional integral derivative (PID) controller was constructed as shown in Figure 7 . The analysis to obtain the eigenvalues and unbalance response was performed for speeds ranging from 0 to $25000 \mathrm{rpm}$, and the damped natural frequency map is as shown in Figure 8. It was predicted that the translational and conical rigid body modes would be passed at a speed 


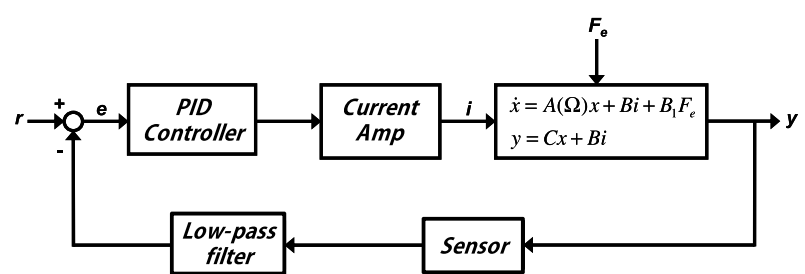

Fig. 7. Block diagram of magnetic bearing control system.

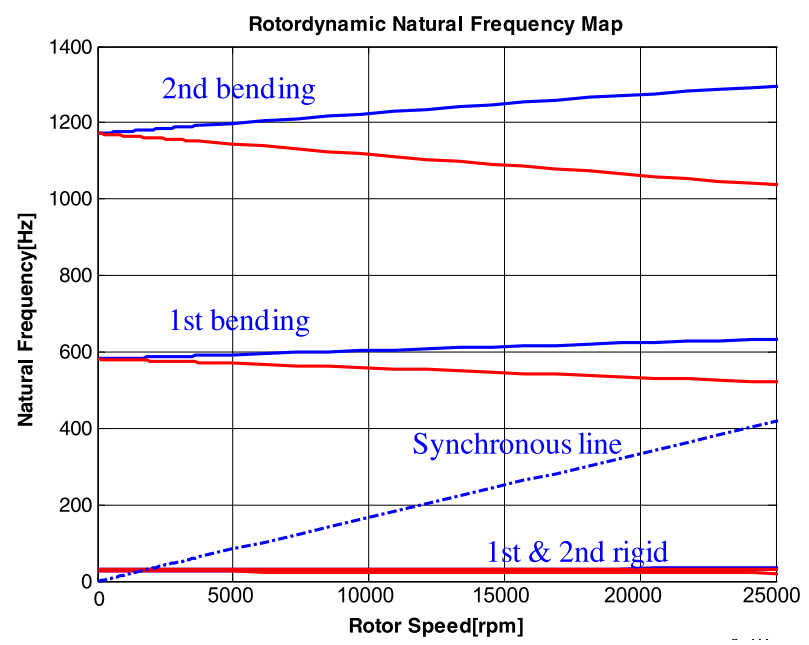

Fig. 8. Predicted damped natural frequency map.

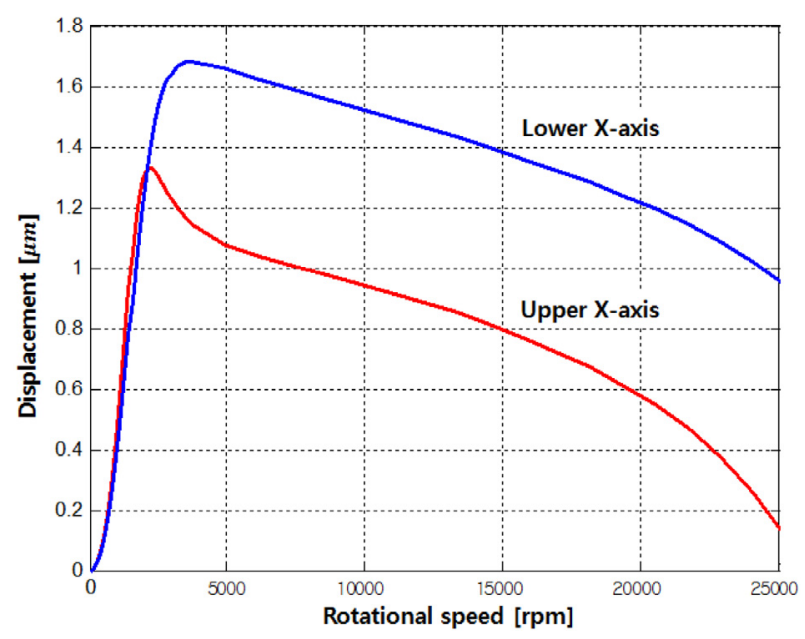

Fig. 9. Predicted unbalance response of rotor.

below $5000 \mathrm{rpm}$ and the frequency of the backward 1st bending mode at $21000 \mathrm{rpm}$ would exist at $533 \mathrm{~Hz}$, which is sufficiently far from the frequency of $350 \mathrm{~Hz}$ corresponding to the operating speed of $21000 \mathrm{rpm}$. The unbalance response was calculated by assuming that the balancing condition satisfies ISO 1940 G2.5 and that the unbalances are evenly located at the 11 th and 32 nd node with a phase difference of $180^{\circ}$. It was predicted that the zero-to-peak displacement of the rotor would be less than $2 \mu \mathrm{m}$ at the location of the radial HMB in all speed ranges (Fig. 9).

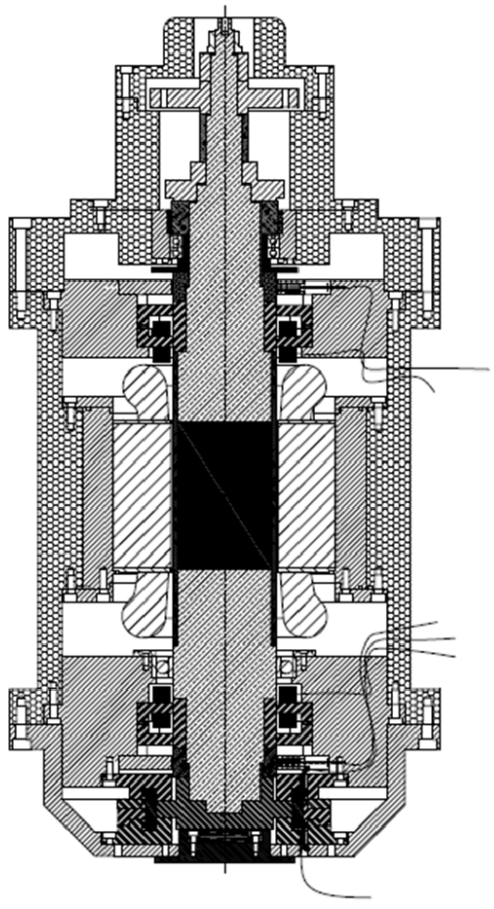

Fig. 10. Cross-sectional view of magnetic bearing test rig.

\section{Performance evaluation of magnetic bearings}

\subsection{Fabrication of magnetic bearing test rig}

The magnetic bearing test rig was designed as shown in Figure 10 and fabricated as shown in Figure 11 to evaluate the designed thrust magnetic bearings. The rotor for the test rig had a dummy mass at the end of the upper shaft instead of the impeller because this test rig was designed only to check the validity of the HMB. The rotor consisted of the rotor shaft, magnet for motor, pure iron core for radial $\mathrm{HMB}$, thrust sensor plate, and pure iron thrust collar. Two gap sensors were placed at the upper housing to measure the axial motion of the rotor by targeting its thrust sensor plate. The axial movements were fed back to the controller after averaging the outputs of the 2 gap sensors.

The control system for the magnetic bearing was implemented by using xPC Target, as shown in Figure 12 [16], and its sampling frequency was $10 \mathrm{kHz}$. In the case of the thrust HMB, 1 degree of freedom (DOF) magnetic levitation can be described by (3) and (4) as follows:

$$
\begin{aligned}
m \ddot{z} & =F \\
F & =-K_{t x} z+K_{t i} i
\end{aligned}
$$

Here $m$ is the rotor mass; $z$, the axial displacement of the mass; $F$, the axial force from the thrust HMB; and $i$, the control current. The initial PID controller was designed by using the abovementioned magnetic levitation model. Here, the attractive force generated by the PMB 


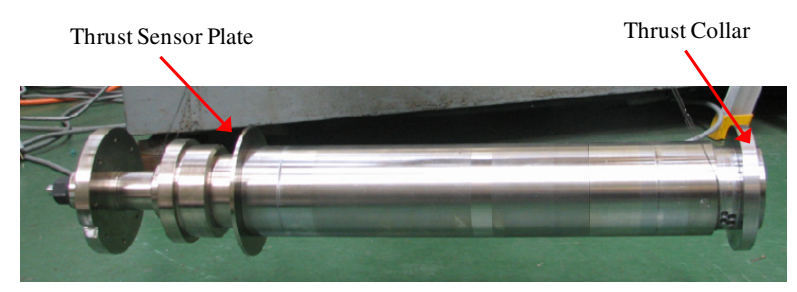

(a)

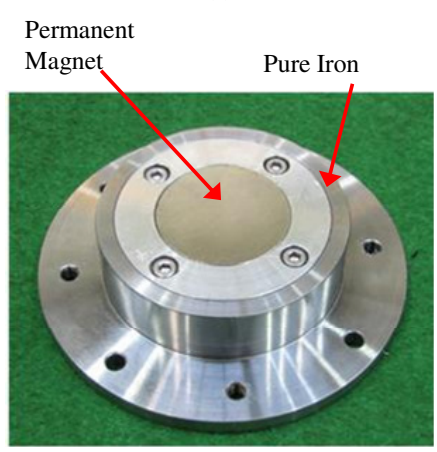

(b)

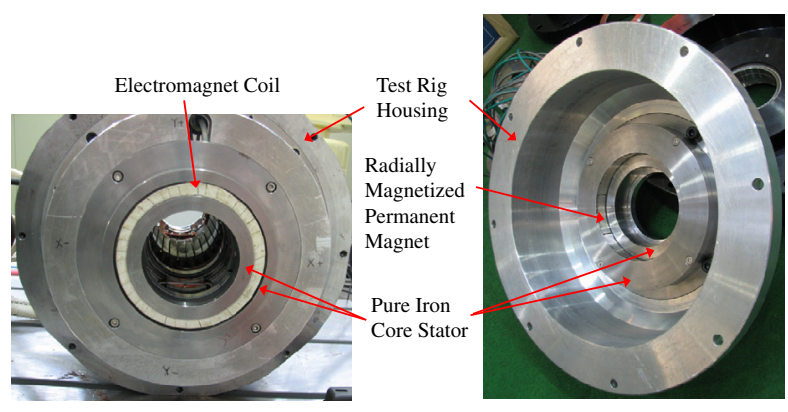

(c)

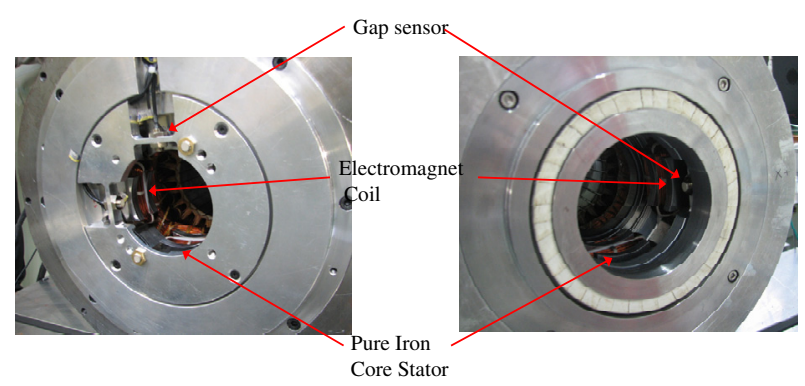

(d)

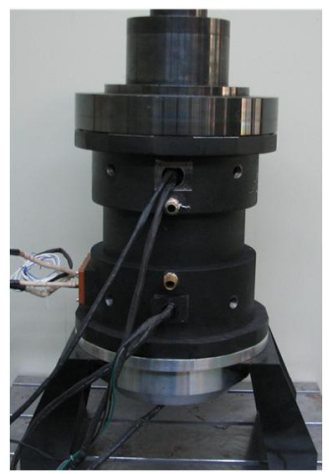

(e)

Fig. 11. Fabricated components and test rig. (a) Rotor; (b) PMB for thrust bearing; (c) Actuator for thrust HMB; (d) Actuator for radial HMB; (e) Test rig.

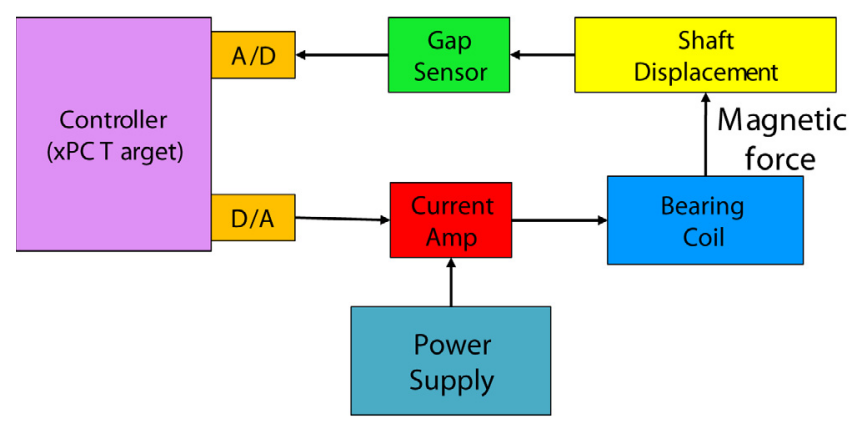

Fig. 12. Configuration of magnetic bearing control system.
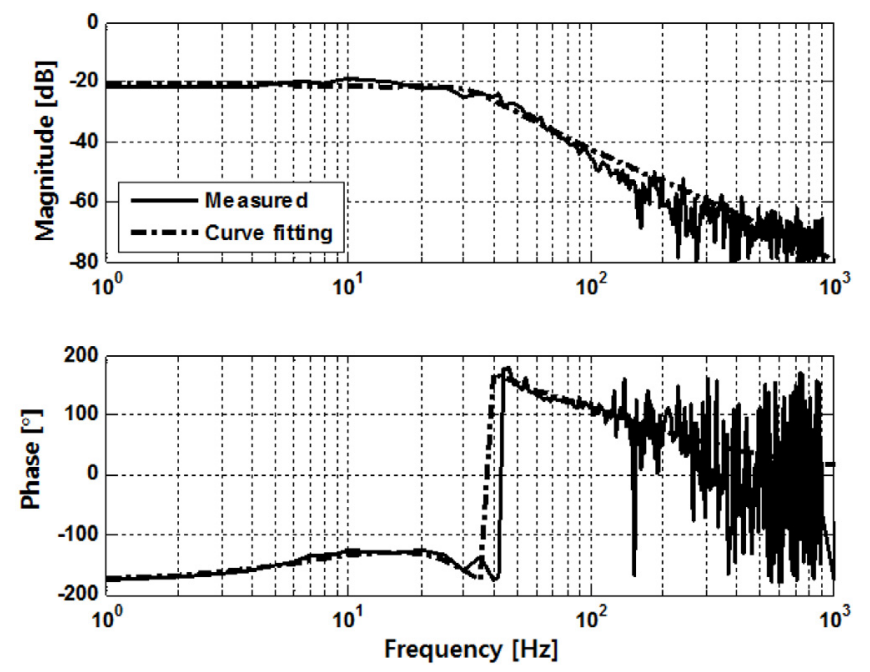

Fig. 13. Measured frequency response functions and curve fitting model of thrust HMB.

was considered as the force disturbance to the control system. The frequency response functions (FRFs) of the thrust $\mathrm{HMB}$ were measured up to $5 \mathrm{kHz}$ by using the swept-sine method. The measured FRFs and the nominal plant model are shown in Figure 13, and they include all the axial dynamics of the rotor, actuator, power amp, and sensor. Based on the nominal plant model, the PID control gains for the thrust HMB are optimized and selected to be 15, 2, and 0.03, respectively, and the PID control gains for the radial HMB are selected in the same manner.

The position error for the reference axial positions in both the time and frequency domains, which is measured at standstill, is shown in Figure 14. The gap between the reference position and mechanical limit was $300 \mu \mathrm{m}$, whereas the standard deviation of the axial position error was less than $5 \mu \mathrm{m}$; this implies that the designed thrust HMB and its controller were working satisfactorily.

\subsection{Running test}

Performance evaluations of the magnetic bearing at speeds of up to $21000 \mathrm{rpm}$ were conducted by using a magnetic bearing test rig and motor inverter. Figure 15 shows the radial unbalance responses of the rotor for 

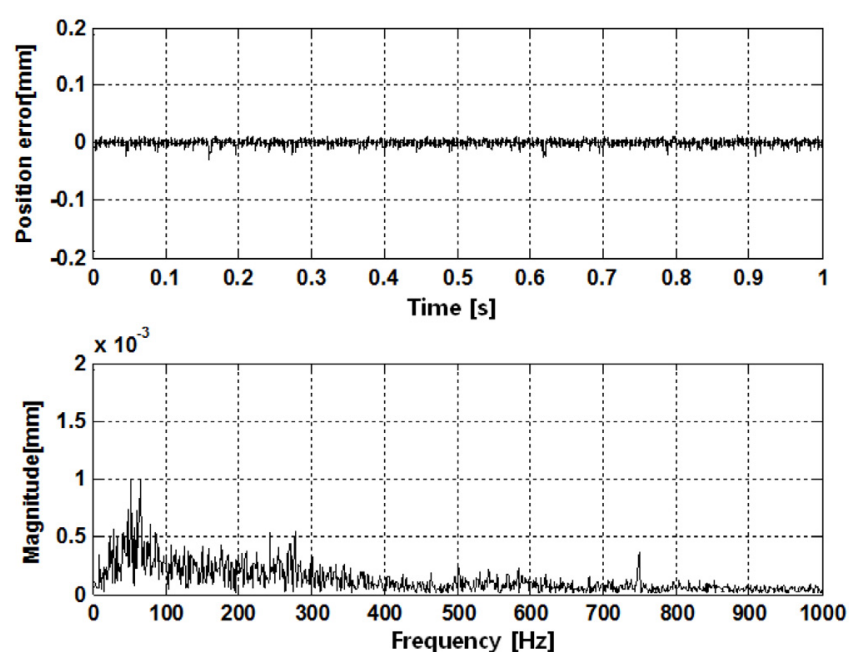

Fig. 14. Control performance of thrust HMB in time and frequency domains.

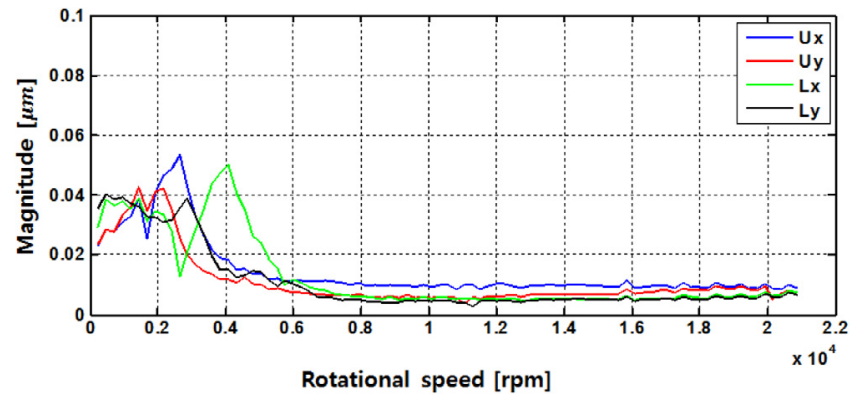

Fig. 15. Radial unbalance responses of rotor for entire range of operational speeds.

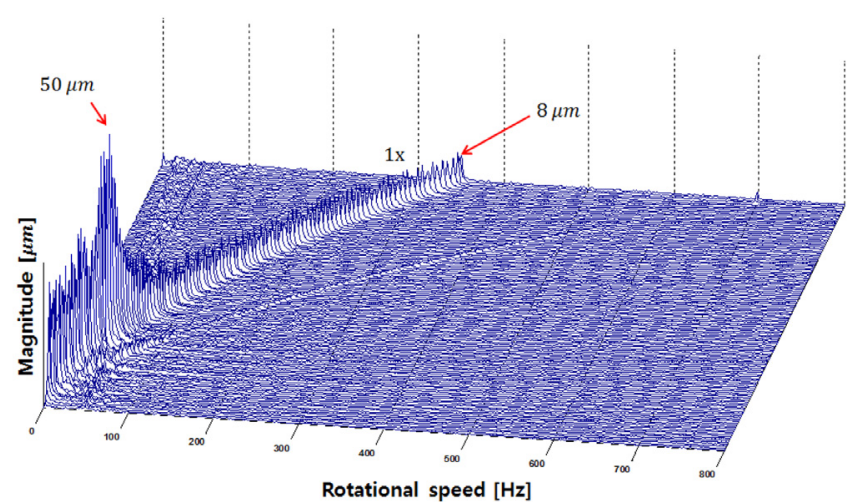

Fig. 16. Waterfall plot of upper radial vibrations for entire range of operational speeds.

the entire range of operational speeds. The rotor passed through the translational and conical modes at 2800 and $4000 \mathrm{rpm}$, respectively. The zero-to-peak radial displacement at $21000 \mathrm{rpm}$ was less than $10 \mu \mathrm{m}$. The waterfall plot of the radial vibration in Figure 16 shows that vibration components other than those for the unbalance response are not noticeable. The waterfall plot of axial displacement shown in Figure 17 indicates the performance of the thrust HMB. The $1 \times$ synchronous component is

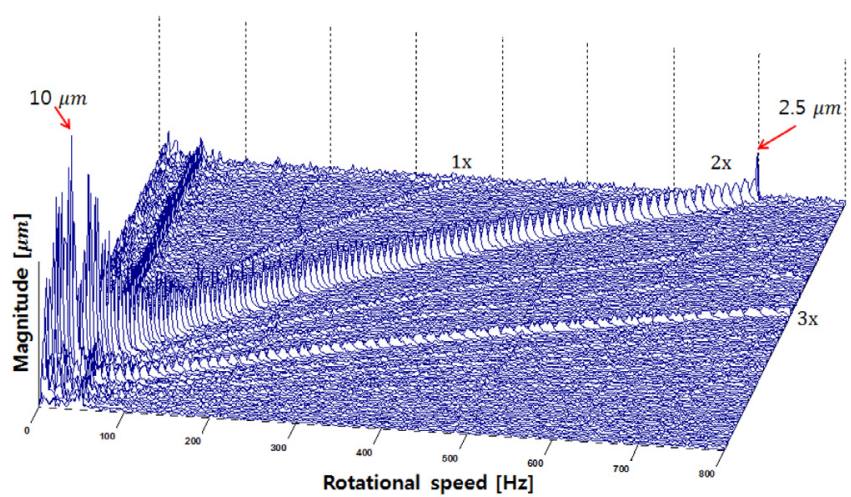

Fig. 17. Waterfall plot of axial vibrations for entire range of operational speeds.

hardly seen, whereas the $2 \times$ synchronous component is very noticeable with the zero-to-peak displacement less than $3 \mu \mathrm{m}$ at $21000 \mathrm{rpm}$. This is because 2 gap sensors are used to measure the axial displacement.

\section{Conclusion}

In this study, magnetic bearings comprising homopolar-type radial HMBs and a thrust magnetic bearing are designed for 145 RT-class turbo refrigerant compressors. To overcome the high upward thrust force of $2000 \mathrm{~N}$ at $21000 \mathrm{rpm}$, the thrust magnetic bearing was made using a thrust HMB and a permanent magnet generating downward forces. Rotordynamics analyses using the finite element method predicted that the 1st bending mode will be located at a high frequency with sufficient margin from the operating speeds. Furthermore, even when a PID controller is used, the zero-to-peak displacement caused by the unbalance response will be sufficiently small and it will run stably over the entire range of operational speeds. The performance of the designed magnetic bearings was evaluated by using the fabricated test rig. The rotor of the test rig was stably supported with few vibrations over the entire range of operational speeds, as predicted. The results of this study demonstrate that the advantages of oil-free bearings can be easily exploited in turbo machineries such as turbo refrigerant compressors by adopting HMBs.

\section{References}

[1] C.R. Knospe, Active magnetic bearings for machining applications, Control Eng. Pract. 15 (2007) 307-313

[2] G. Schweitzer, Applications and research topics for active magnetic bearings, IUTAM Symposium on Emerging Trends in Rotor Dynamics, Springer, Netherlands, 2011, pp. $263-273$

[3] C. DellaCorte, A.R. Zaldana, K.C. Radil, A systems approach to the solid lubrication of foil air bearings for oilfree turbomachinery, J. Tribol. 126 (2004) 200-207 
[4] H. Asakura, N. Saji, S. Yoshinaga, T. Ishizawa, M. Ikeuchi, H. Yanagi, Y. Hirao, K. Kitagawa, Development of a highly reliable helium refrigeration system-R\&D of a highly reliable helium refrigeration system (oil-free type), Cryogenics 42 (2002) 203-208

[5] J.S. Rao, R. Tiwari, Design optimization of doubleacting hybrid magnetic thrust bearings with control integration using multi-objective evolutionary algorithms, Mechatronics 19 (2009) 945-964

[6] W. Morales, R. Fusaro, A. Kascak, Permanent magnetic bearing for spacecraft applications, Tribol. Trans. 46 (2003) 460-464

[7] J. Fang, Y. Le, J. Sun, K. Wang, Analysis and design of passive magnetic bearing and damping system for high-speed compressor, IEEE Magn. Trans. 47 (2012) 4734-4739

[8] H. Hirai, M. Hirokawa, S. Yoshida, Y. Kamioka, A. Takaike, H. Hayashi, H. Okamoto, Y. Shiohara, Development of a neon cryogenic turboexpander with magnetic bearings, AIP Conf. Proc. 1218 (2010) 895-902

[9] L. Sun, H. Lin, Device to relieve thrust load in a rotorbearing system using permanent magnets, WIPO Patent No. 2004007984. Geneva, Switzerland

[10] C.H. Park, S.K. Choi, J.H. Ahn, S.Y. Ham, S. Kim, Thrust Hybrid Magnetic Bearing using Axially Magnetized Ring Magnet, J. Magn. 18 (2013) 302-307
[11] A.C. Lee, F.Z. Hsiao, D. Ko, Analysis and testing of magnetic bearing with permanent magnets for bias, JSME Int. J. Ser. C 37 (1994) 774-782

[12] A.C. Lee, F.Z. Hsiao, D. Ko, Performance limits of permanents-magnet-biased magnetic bearings, JSME Int. J. Ser. C 37 (1994) 783-794

[13] E.H. Maslen, P.E. Allaire, M.D. Noh, C.K. Sortore, Magnetic bearing design for reduced power consumption, J. Tribol. 118 (1996) 839-846

[14] Y.H. Fan, A.C. Lee, Design of a permanent/electromagnetic magnetic bearing-controlled rotor system, Journal of the Franklin Institute 334 (1997) 337-356

[15] S.Y. Yoo, C.H. Park, S.K. Choi, M.K. Noh, Identification of flexible rotor modeling for a large capacity flywheel energy storage system, Proceedings of 15th International Congress on Sound and Vibration, Daejeon, Korean, 2008, pp. 1042-1049

[16] C.H. Park, S.K. Choi, Y.S. Son, Y.H. Han, Development of $5 \mathrm{kWh}$ flywheel energy storage system using MATLAB/xPC Target, Proceeding of the WRI World Congress on Computer Science and Information Engineering, Los Angeles, California, 2009, pp. 701-705 